\title{
Morphotectonic aspects in a part of Naga-Schuppen belt, Assam-Nagaland region, Northeast India
}

\author{
Farha Zaman,* Devojit Bezbaruah \\ Department of Applied Geology, Dibrugarh University, Dibrugarh 786004, Assam, India
}

\begin{abstract}
The Belt of Schuppen is an important tectonic element of the Assam-Arakan basin. It is a narrow belt of thrust slices in southeastern boundary of the Assam valley. The Naga Schuppen Belt, consisting of eight or more imbricated thrusts, occurs between the Naga and Disang thrusts. This present study encompasses an area of $4,720 \mathrm{sq} \mathrm{km}$ along the Assam-Nagaland border. The Dikhow River, which is a seventh order basin, originates from Naga Hills flowing through a total length of $240 \mathrm{~km}$ in the Assam valley and reaches the Brahmaputra. In this study, the morphotectonic analysis of the Dikhow River was carried out to understand the role of active tectonics of the Naga Hills in Nazira-Naginimora areas of Assam and Nagaland respectively. The parameters such as asymmetric factor (AF), transverse topographic symmetric factor $(\mathrm{T})$, and stream length gradient index $(\mathrm{SL})$ were computed. Absolute AF values shows asymmetric to highly asymmetrical shape of the basins (range III-IV) which is also supported by T values. Anomalous SL values were obtained wherein major lineament and tectonic features are present. This indicates that the study area is tectonically active. Further, in the Assam valley it has been observed in the bank stratigraphy of Dikhow River that the Quaternary sediments are deformed. This deformation of the soft older alluvium indicates that the area is undergoing deformation during post Pliocene time. This evidence demands the morphotectonic evaluation of the aforesaid area to demarcate the tectonic activeness of the region in post Pliocene times.
\end{abstract}

Keywords: Active tectonics, asymmetric factor, Naga Hills, lineaments.

\section{Introduction}

The Belt of Schuppen (BoS) in the western part of Nagaland forms the most prominent morphotectonic unit of the Naga Hills covering an area of $4,500 \mathrm{sq} \mathrm{km}$. It constitutes the outermost morpho-tectonic unit of the Assam-Arakan fold belt which formed as a result of subduction of the Indian plate beneath the Burmese plate. ${ }^{1,2}$ Mathur and Evans opined that the Tertiary sediments of this belt were deformed by eight or possibly more thrust slices. ${ }^{3}$ They are overriding each other which is evidenced by Naga Hills as it thrusted north- westward relative to the Precambrian crystalline Foreland Spur.

This paper aims to evaluate the neotectonic evidences and morphotectonic analysis in and around the Nazira-Naginimora region by tracing the changes in the course of Dikhow River supplemented by major surface anomalies (Figure 1). To carry out this study, morphotectonic parameters were used to understand the presence of active tectonics for the area.

Nazira is a historical town on the bank of the 


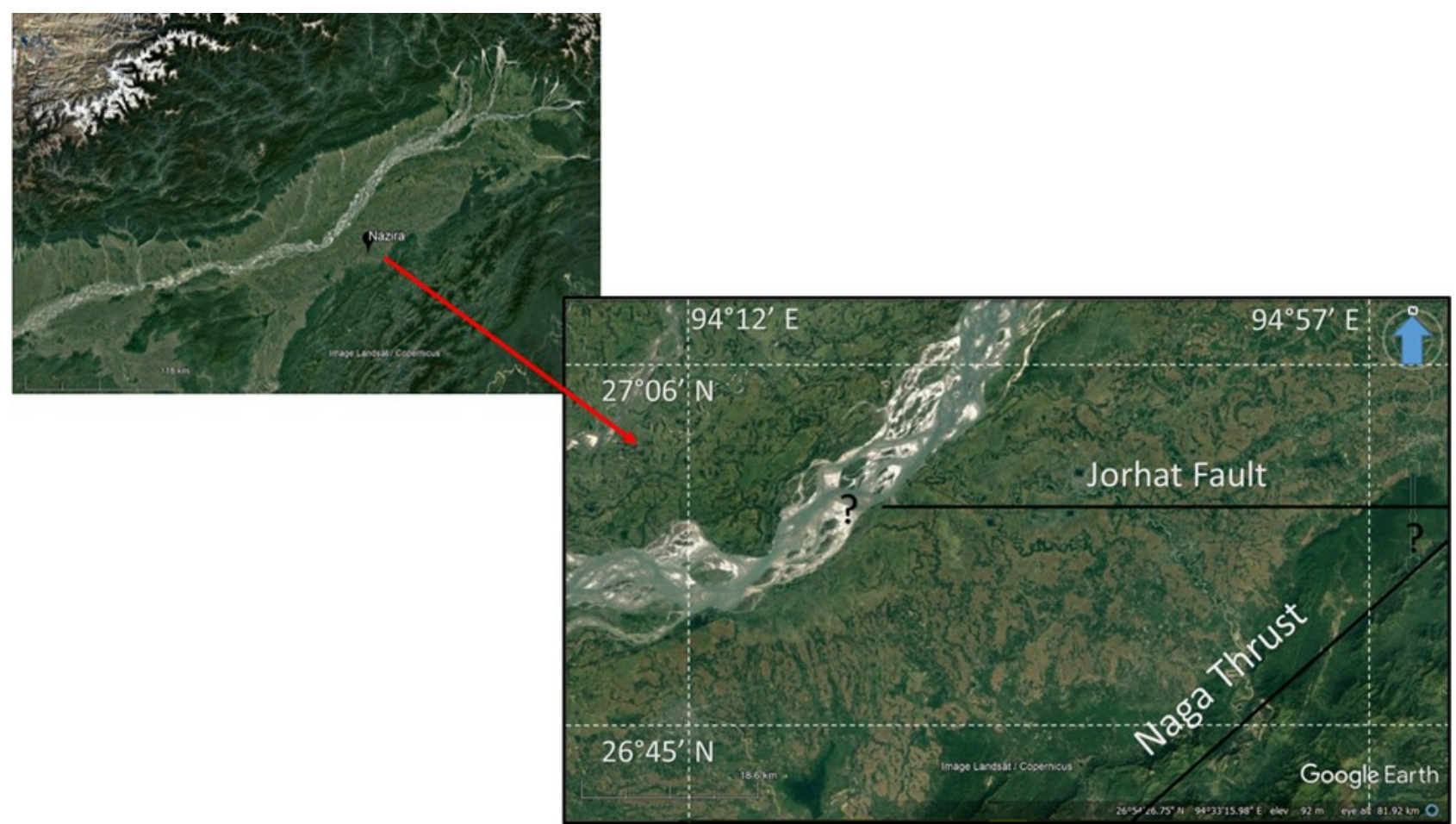

Figure 1 | Location map for Nazira-Naginimora area of Assam-Nagaland.

River Dikhow. It is located at $26.92^{\circ} \mathrm{N} 94.73^{\circ} \mathrm{E}$. It has an average elevation of 132 meters (433 ft.) Naginimora is a town in Nagaland located at $26.48^{\circ}$ $\mathrm{N} 94.48^{\circ} \mathrm{E}$. It shares border with Assam. The location of field study is confined to the Nazira-SimoluguriNaginimora road section located in the Sibsagar district of Assam and Mon district of Nagaland. The study area is bounded by $26^{\circ} 40^{\prime} \mathrm{N}$ and $27^{\circ} 00^{\prime} \mathrm{N}$ latitudes and $94^{\circ} 40^{\prime} \mathrm{E}$ and $95^{\circ} 00^{\prime} \mathrm{E}$. The area under study is included in the Survey of India of the year 1975 toposheet no. $83 \mathrm{l} / 8,83 \mathrm{l} / 12,83 \mathrm{~J} / 5,83 \mathrm{~J} / 6,83$ $\mathrm{J} / 7,83 \mathrm{~J} / 9,83 \mathrm{~J} / 10,83 \mathrm{~J} / 11,83 \mathrm{~J} / 13,83 \mathrm{~J} / 14,83 \mathrm{~J} / 15,83$ $\mathrm{N} / 1,83 \mathrm{~N} / 2$ and $83 \mathrm{~N} / 3$ of $1: 50,000$ scale.

It was observed that before entering, Nazira the bank of Dikhow River is quite high. The NaziraSimoluguri towns lie close to Dikhow River but are not inundated during high stage of the river i.e. they are above the active floodplain. The plain areas consist of older alluvium, which is underlain by a succession of Tertiary sedimentary rocks deposited in a shelf environment above the Precambrian granitic basement. The topography in the southeastern part is undulatory. The undulation in the older floodplain is mainly due to erosion of the overland flow. This indicates that the area has been uplifted above the present floodplain of Dikhow River. Therefore, it can be inferred that a splay from the Naga thrust uplifted this area which further supports the fact that the area is undergoing active tectonics.

\section{Materials and Methods}

The study of the area was based on Survey of India topographic maps (1:50000), extensive field surveys and software compiling works. The data obtained were based on field observations of several outcrops that were collected by traversing in Nazira, Simoluguri and Naginimora areas. The attitude of the different beds was measured with the help of Brunton compass.

Global positioning system (GPS) was used to get the location of the stations. Digitization of field data requires the preparation of geological cross-section, digitization of maps and calculation of the morphometric indices etc. ASTER GDEM (30-meter resolution) data was used to get the elevation data to understand the topographic variations and morphotectonic indices. The knowledge of topographic variation of the area was obtained from topographic maps, Google earth maps, and ASTER GDEM data.

Satellite images from Google Earth were used to understand the nature of the terrain in the area of interest. Morphotectonic study of the area has been done with the help of the parameters like asymmetric factor, transverse topographic symmetry factor and stream length gradient index supplemented by lineament data. Drainage patterns were drawn and evaluated as they indicate the presence of anomalous zones, to delineate the 
Table 1 : Morphotectonic parameters for Dikhow and its prime sub-basins.

\begin{tabular}{|lcccc}
\hline Basins & Order & $\begin{array}{c}\text { Absolute asymmetric } \\
\text { factor }\end{array}$ & $\begin{array}{c}\text { Transverse topographic } \\
\text { symmetry factor }\end{array}$ & Stream length gradient \\
\hline Dikhow Sub-Basin & $6^{\text {th }}$ & $0.32-36.17$ & $0.09-0.88$ & $371.03-59680.6$ \\
\hline Yangnyu Sub-Basin & $6^{\text {th }}$ & $1.18-29.21$ & $0.05-0.44$ & $226.214-56055$ \\
\hline Dikhow Basin & $7^{\text {th }}$ & $0.32-36.17$ & $0.05-0.90$ & $61.8823-59680.6$ \\
\hline
\end{tabular}

structural or lithological control over the study area. Asymmetry factor (AF) was developed to detect the tilting transverse to flow of the channels. It was calculated by using the formula,

$$
\mathrm{AF}=100 \times(\mathrm{Ar} / \mathrm{At})
$$

where, Ar is the area of the basin to the right (facing downstream) of the trunk stream, and At is the total area of the drainage basin. Absolute AF value (|AF|) of a basin refers to those values that are obtained by subtracting from 50 the values of $A F$ for the respective basins, i.e. $|50-\mathrm{AF}|{ }^{4}$

Transverse topographic symmetry factor $(T)$ is a quantitative index and it is calculated from the equation $\mathrm{T}=\mathrm{Da} / \mathrm{Dd}$; where, $\mathrm{Da}$ represents the distance from the midline of the drainage basin to the midline of the active meander belt and $\mathrm{Dd}$ corresponds to the distance from the basin midline to the basin divide. ${ }^{5}$ The stream length-gradient index (SL) is calculated using the formula:

$$
\mathrm{SL}=(\Delta \mathrm{H} / \Delta \mathrm{L}) \mathrm{L}
$$

where $L$ is the total channel length from midpoint and $\Delta \mathrm{H} / \Delta \mathrm{L}$ is the channel slope on that part of the channel where the reading is taken., ${ }^{4,6}$ The lineaments are drawn using SOl toposheets (scale $1: 50,000)$ and on DEM. All these parameters are illustrated with the help of different figures.

\section{Results and Discussion}

Tectonic perturbances in a region leaves many signatures on the surface of earth which can be evaluated for better understanding of the surface and sub-surface anomalies. ${ }^{4}$ The deformations and their level of intensity is what makes the region fall under the category of being tectonically active. Morphotectonic parameters acts as a source for studying the activeness of a region in depth. Morphotectonic evaluation of the present study area involves the study of the basins of the Dikhow River with respect to its tilting pattern, tilting direction, gradient change and presence of linear features. Studying drainage system provides information on the long-term evolution of the landscape. ${ }^{9}$ The slope is the function of tilting hence the basin asymmetry can be used to decipher the tilting of the area, thereby helping in neotectonic studies. ${ }^{5,10}$ The data provided by asymmetric factor and transverse topographic symmetry factor helps to quantify the distinctive stream patterns and geometries. It has been observed that all the absolute values of drainage basin asymmetry ranges between 0.32 to 36.17 (Table 1). Most of the basins shows |AF| range III-IV which indicates prevalence of high tectonic activity in the area as the basin shows moderate to high asymmetry. The highest asymmetric value of 36 is a clear evidence to this. The tilting direction of the basin is towards NW along with some showing NE and SE tilting. The higher order sub-basins indicate high asymmetry with tilting towards NW directions (Figure 2).

The $T$ values show similar result like that of $A F$. The $T$ value ranges between 0.05 to 0.9 . Here also tilting direction is mostly NW and channels are shifted closer to the drainage divide in some highly tilted basins. Few basins indicate less tilting than others and have very low $\mathrm{T}$ values.

The entire region being under the prevalence of Naga Thrust and Disang thrust on a regional scale along with a few local thrusts is thereby tectonically active. The region is under both structural and lithologic control. Presence of argillaceous rocks makes it highly susceptible to erosion which complies with the drainage anomalies. Thus, it can be stated from all the points that all the major thrusts and other fault-fold system of the area is active and controls the geometry and geology of the basins.

The SL index is applied to identify recent tectonic activity by recognizing high index values variations on a particular rock type. In the present study SL index values are calculated in different segments for the same basin. The high and low anomalous SL points marked in the plots for each basin are shown in the map along with the micro and macro lineaments (Figure 3). The anomalous points are lying parallel, across or even lying upon the major lineament trends of the region. Most of the high anomalous points lie in NE direction in a linear pattern. Some other low anomalous zones along with few high anomalous points lie along NW direction. Irrespective of the basin order, the high anomalous points are controlled by the major lineaments of the area which is also same as regional tectonic setting. The rise of the Naga Hills and the NE stress component of the subducting Indian plate has a direct control over the major lineaments and 


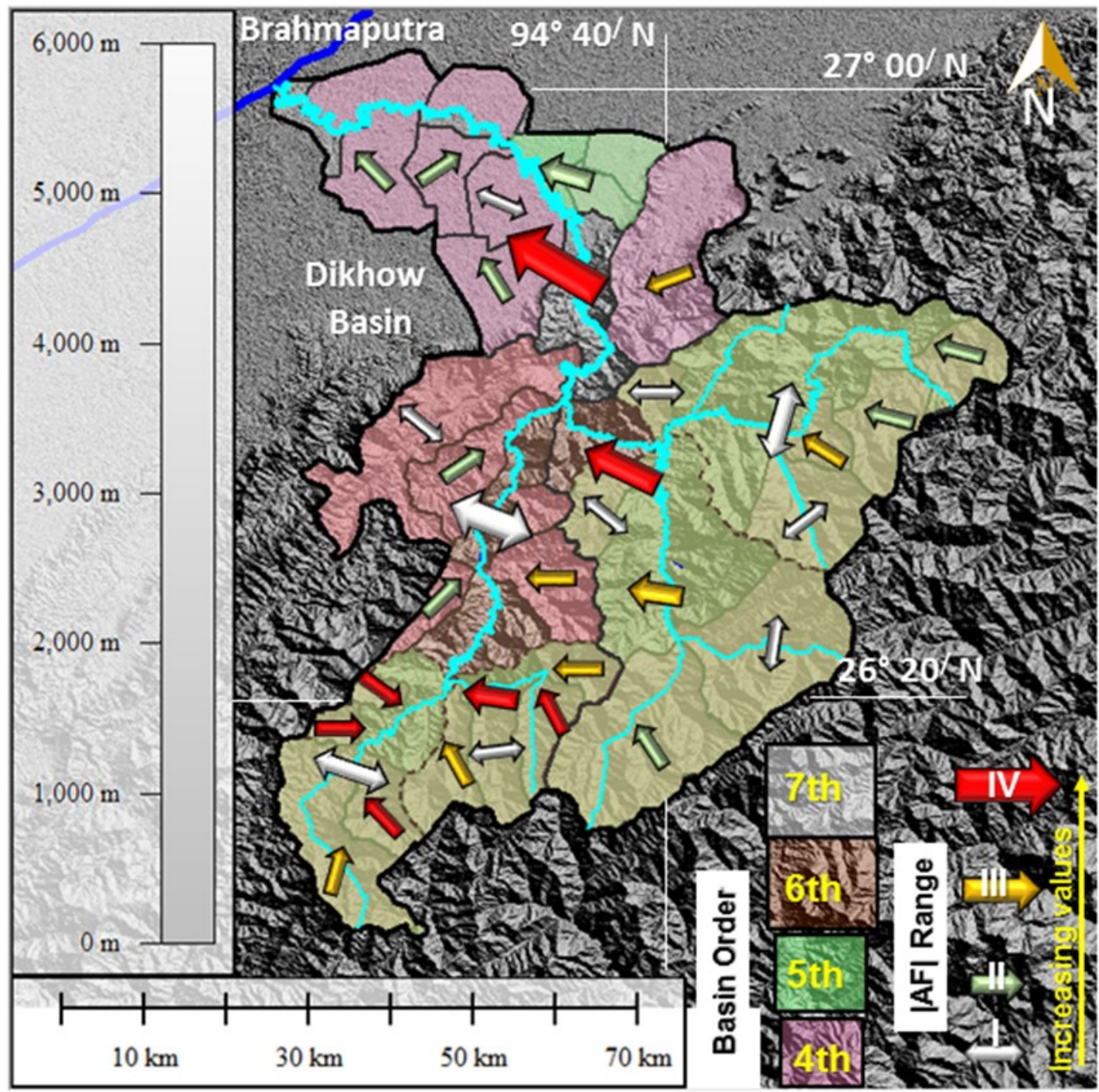

Figure 2 | Absolute AF ranges have been shown for different basin of the Dikhow River. The arrows are showing the tilting direction of the basins (from AF and T) along with their asymmetric range.

furthermore, to the high anomalous SL zones of the area. These high anomalous zones should be considered as tectonically and structurally controlled regions. The low anomalous points are evident of the main tectonic activity of the region although in few cases lithological and local control can be obtained from the lower anomalous points in the study area. So, low anomalous zones are probably indicative of lithologic and local control of the area which is evident from their relation with micro lineaments of the area.

From the above results it can be stated that the Dikhow River along with the sub- basins are showing high $A F$ and $T$ values that clearly indicates that the basin area is tectonically active. The SL values and the relationship of high and low anomalous SL points with the structurally and lithologically active features provides more evidences for the presence of tectonically active surface and sub-surface factors. The drainage pattern of the different channels associated with the main river (Figure 2 ) and active fault systems (Figure 3) also shows correlations among them. Therefore, morphotectonic parameters and other factors helps to infer that the study area in this part of Naga Hills is being shaped and deformed by tectonically active features.

\section{Conclusion}

In the study area, certain evidences were observed which indicated that the area has been undergoing recent tectonic activity and deformations. Different morphotectonic parameters along with their evidences of recent tectonic movements such as major trend in the lineaments in the study area, and sinuosity of the Dikhow River are 


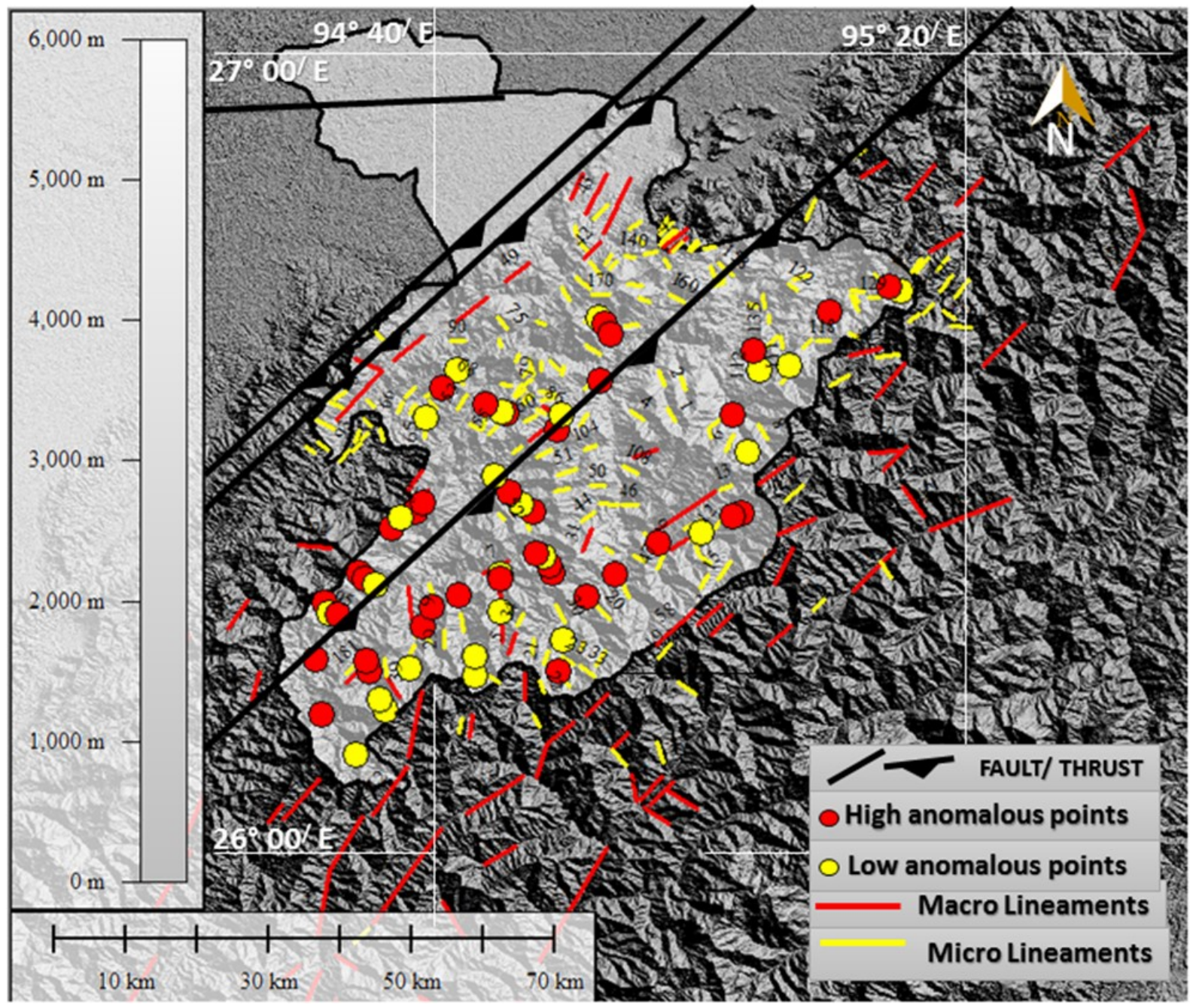

Figure 3 | Lineament map of the study area along with the anomalous SL points embedded in it.

studied. In the present study area, the anomalous SL points provides both high and low anomalous zones. They are found to be correlated with macro- and micro-lineaments of the regions. Lineaments are topographic expression of subsurface activities. The macro lineaments showing prominent NE component is similar with major tectonic features in the area. The structural control is dominantly shaping the topography and are found to be influencing the micro-lineament patterns, which also shows affinity to lithological variations. Most of the basins are moderate to highly asymmetrical with some symmetrical basins also being encountered. The AF and $T$ values indicate the presence of active tectonics in the region. The continuous Indian plate movement which once exhumed the Naga hill ranges are still shaping the region including the Dikhow basin. Overall the active tectonic study is important for the area which unravel the mysteries of early tectonic movement. Some morphometric parameters which are showing low activity should be used carefully in the similar kind of study areas. This study is supposed to be useful for many geomorphic works, hazard zonation, and development policy and even in petroleum industry. This work has many future scopes which can be done in addition to this study.

\section{REFERENCES}

1. Das Gupta, A.B., Biswas, A.K. (2000). Geology of Assam. Geological Society of India, Bangalore, p. 1 -20 .

2. Evans, P. (1964). The Tectonic Framework of Assam. 
Geological Society of India, pp. 22-64.

3. Mathur, L.P. \& Evans., P. (1964). Tertiary Sedimentary Study of NE India. Oil in India. 2nd International Geological Congress, New Delhi, pp. $1-85$.

4. Keller, E. A. \& Pinter, N. (2002). Active Tectonics: Earthquakes, Uplift, and Landscape (2nd edition). New Jersey: Prentice Hall, pp. 80-90.

5. Cox, R. T. (1994). Analysis of drainage basin symmetry as a rapid technique to identify areas of possible Quaternary tilt-block tectonics: an example from the Mississippi Embayment. Geological Society of America Bulletin 106 (5), 571581.

6. Azor, A., Keller, E. A. \& Yeats, R. S. (2002). Geomorphic indicators of active fold growth: South Mountain-Oak Ridge anticline, Ventura basin, southern California. Geological Society of America Bulletin 114 (6), 745-753.

7. Hack, J.T., (1973). Stream-profile analysis and stream gradient index. United States Geological Survey Journal of Research 1 (4), 421-429.

8. Ramírez-Herrera, M.T. (1998). Geomorphic assessment of active tectonics in the Acambay Graben, Mexican volcanic belt. Earth Surface Processes and Landforms 23, 317-332.

9. Burbank, D. W., \& Anderson, R. S. (2011). Tectonic Geomorphology. John Wiley \& Sons, pp. 1-60.

10. Hare, P. W. and Gardner, T. W. (1985). Geomorphic indicator of vertical neotectonism along converging plate margins, Nicoya Peninsula, Costa Rica. In Tectonic Geomorphology: Proceedings of the $15^{\text {th }}$ Annual Binghamton Geomorphology Symposium, 15, pp. 75-104. 